\title{
Sensitivity study of horizontal length, offset from water oil contact and withdrawal rate of horizontal well in bottom water drive reservoir
}

\author{
Manish Kumar' ${ }^{1}$ Pushpa Sharma $^{2}$ D. K. Gupta ${ }^{2}$
}

Received: 19 January 2017/Accepted: 10 April 2017/Published online: 29 April 2017

(C) The Author(s) 2017. This article is an open access publication

\begin{abstract}
Estimation of critical rate is required for maximizing oil production from horizontal well before water breakthrough. Post-breakthrough recovery is dependent on parameters viz: Horizontal length (L), withdrawal rate (Q) and offset from WOC (h). Critical rate has been determined using various analytical methods whereas EUR from horizontal well has been calculated for forty-eight cases (L-4 no's, Q-3 no's, h-4 no's) using commercial black oil simulator. Result of the study shows that maximum impact on cumulative oil production is given by offset from WOC followed by withdrawal rate and lastly on horizontal well length.
\end{abstract}

Keywords Coning · Offset - Horizontal completion · Water-free production $\cdot$ Sensitivity

\section{Introduction}

Excessive water production from hydrocarbon reservoirs is one of the most serious problems in matured oil fields. Besides the down fall of oil production rate and wastes of reservoir energy, operating cost of in the surface production operations also increases due to handling, treatment, and disposal of large quantities of produced water (Sharma et al. 2009; Al Hasani et al. 2008). Horizontal wells have been used to produce thin zones, fractured

Manish Kumar

manish@oilindia.in

1 Centre of Excellence for Energy Studies, Oil India Limited, Guwahati 780122, India

2 University of Petroleum and Energy Studies, Dehradun 248 007, India reservoirs, formations with water and gas coning problems, waterflooding, heavy oil reservoirs, gas reservoirs, and in EOR methods such as thermal and $\mathrm{CO}_{2}$ flooding (Joshi 2003).

The maximum water-free production rate, referred to as the critical fluid production rate (CFPR), is a function of the thickness of the oil zone, the length of the completion interval, the distance between the completion interval and the water zone, the density of the oil and water, the viscosity of the oil and the formation permeability (Piper and Gonzalez 1987).

Recovery maximization from horizontal well completion is a challenge in the oil industry, which is dependent on variants viz: critical rate, length of horizontal section, offset from water oil contact (WOC), withdrawal rate.

Dikken (1990) first presented and modeled the pressure drop in horizontal well and its effect on the performance of horizontal well, Hyun studied for integrated optimization on long horizontal well length, and Zifei et al. (1997) developed a model for optimal horizontal well length using an coupled model of reservoir and wellbore hydraulics, whereas Hu et al. (2000) presented that of model using net present value (NPV) method.

Efros (1963) proposed a critical flow rate correlation that is based on the assumption that the critical rate is nearly independent of drainage radius. The correlation does not account for the effect of the vertical permeability (Ahmed Tarik 2010). Karcher (1986) proposed a correlation that produces a critical oil flow rate value similar to that of Efros' equation. Again, the correlation does not account for the vertical permeability (Ahmed Tarik 2010). Joshi (1988) determined the critical oil flow rate in horizontal wells by defining the following parameters: horizontal well drainage radius, half the major axis of drainage ellipse, effective wellbore radius (Ahmed Tarik 2010). 


\section{Problem description}

Horizontal Well-49 is located in the southwestern part of the field (Fig. 1). It was drilled and completed in the year 2007. Open-hole logs indicated that the original WOC was at a depth of $2551 \mathrm{~m}$ TVDSS. The landing point was kept at $2540 \mathrm{~m}$ true vertical depth below sea level (TVDSS). The well started production from April 2007 to August 2011 at $140 \mathrm{~m}^{3} / \mathrm{d}$. Initially, the production rate was kept at $140 \mathrm{~m}^{3} / \mathrm{d}$ (7 $\mathrm{mm}$ bean), which was increased further to $170 \mathrm{~m}^{3} / \mathrm{d}(8 \mathrm{~mm}$ bean $)$. It can be seen from Fig. 2 that water started coming after increasing the production rate by increasing the drawdown by increasing the bean size. Well water cut started thereafter, reached a level of $60 \%$, and finally watered out. A diagnostic plot for the verification of the cone has been prepared and presented as shown in Fig. 3. In order to mitigate water production and maximize production determination of critical rate (pre-breakthrough performance) and production profile generation using commercial reservoir simulator (post-breakthrough performance) needs to be carried out by doing sensitivity analysis on horizontal length, withdrawal rate and offset from WOC.

\section{Proposed methodology}

In this paper, following methodology has been adopted for determination of optimum horizontal completion parameters.

A. Initial estimation of CFPR using various analytical methods

B. Numerical simulation modeling

C. Model validation using history matching

D. Sensitivity Analysis
a. Withdrawal rates
b. Offset from WOC
c. Horizontal length

E. Results and discussion

F. Conclusion and recommendations

\section{Initial estimation of CFPR using various methods}

Methods for calculating critical rate using Efros, Krachers, and Joshi's method were used to calculate the CFPR (Ahmed Tarik 2010). All the calculations will be performed using the actual reservoir fluid and rock properties reported in Table 1.

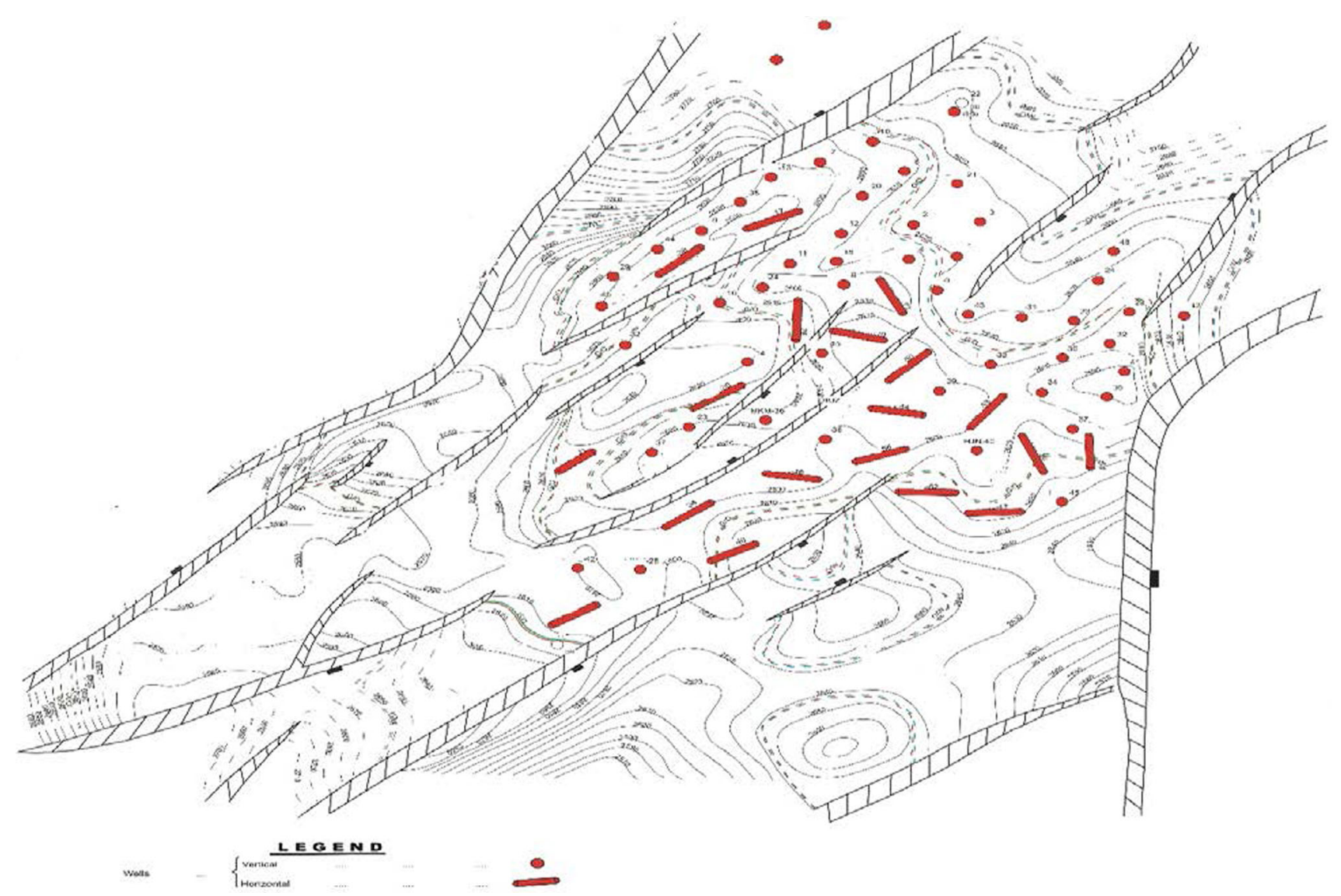

Fig. 1 Depth contour map on top of Oligocene sand 


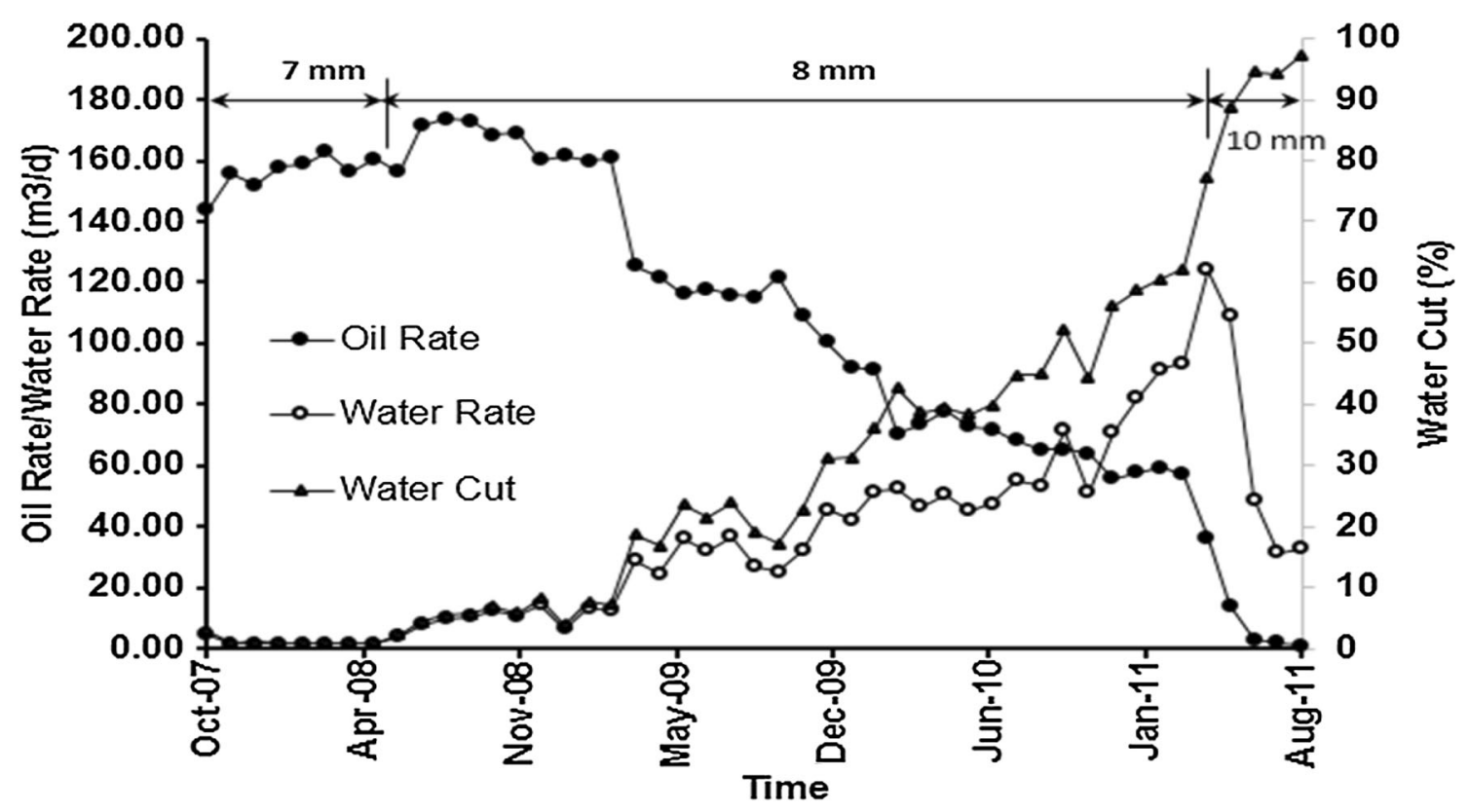

Fig. 2 Production behavior of well-49

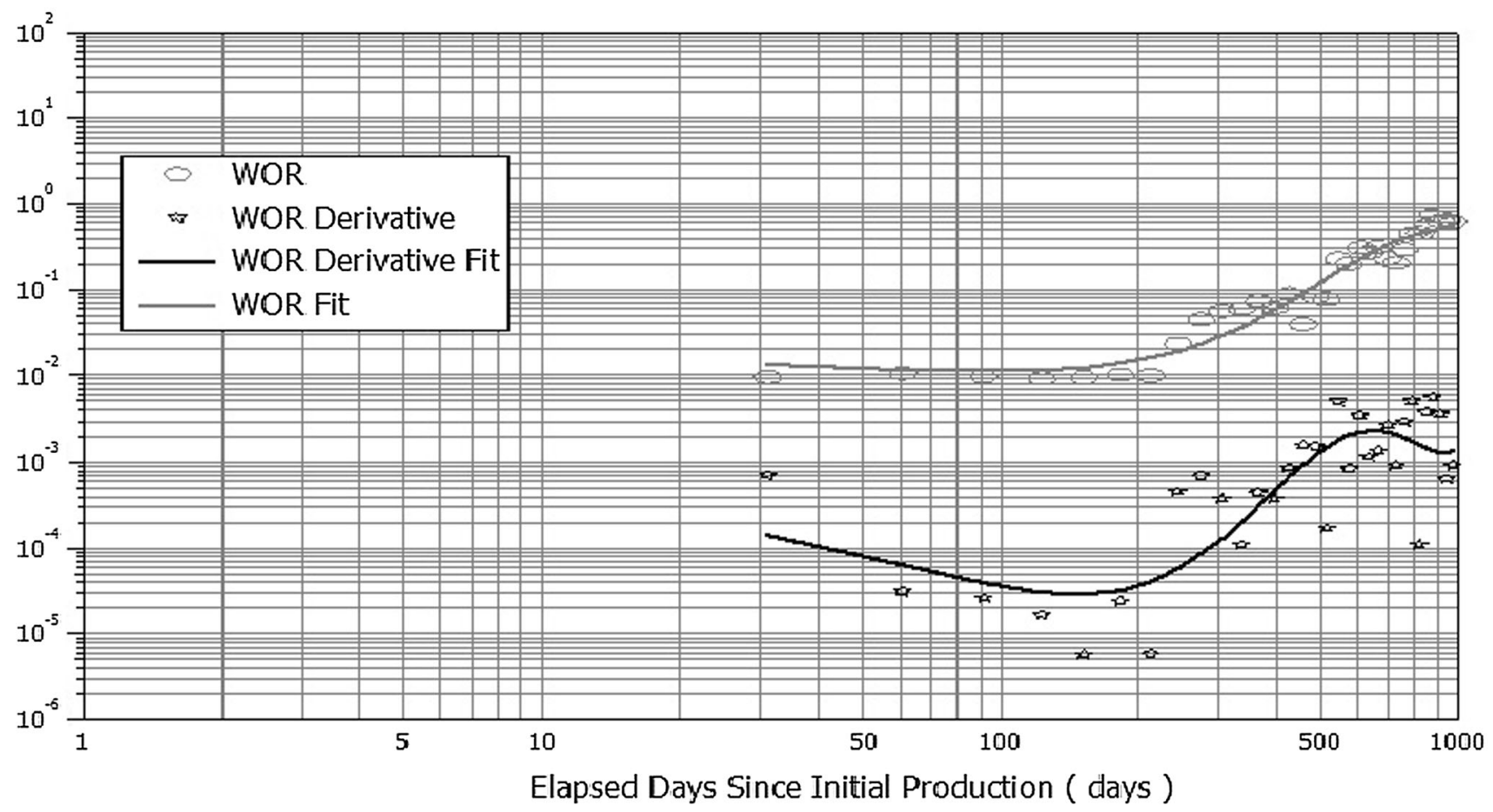

Fig. 3 Water control diagnostic plot of well-49

Efros method for critical rate calculation method

Qoc $=0.0783 \times 10^{-4}\left[\frac{\varrho w-\varrho o}{Y_{e}+\sqrt{Y_{e}^{2}+\left(\frac{h^{2}}{3}\right)}}\right]\left(\frac{K h L}{\mu_{o} B_{o}}\right)\left(h-\left(h-D_{b}\right)^{2}\right)$ where $K$ is permeability in $\mathrm{mD}, h$ is net pay thickness, Ye is half distance between two lines of horizontal well, $L$ is length of horizontal well, and $\varrho$ is density in $\mathrm{lb} / \mathrm{ft}^{3}$.

Krachers method for critical rate calculation method: 
Table 1 Reservoir and fluid properties

\begin{tabular}{ll}
\hline Reservoir properties & \\
\hline Drainage radius, Re(Feet) & 1320.00 \\
Horizontal permeability(md) & 100.00 \\
Vertical permeability (md) & 5.00 \\
Pay zone thickness (Feet) & 98.43 \\
Standoff from WOC, Dt(Feet) & 65.62 \\
Completed interval, hp(Feet) & 60.00 \\
Average reservoir pressure, P(Psi) & 3769 \\
Formation porosity, $\phi(\%)$ & 22 \\
Wellbore radius, Rw(Feet) & 0.23 \\
Length of horizontal well, L (Feet) & 2625 \\
Half drainage length, Ye (Feet) & 656 \\
Fluid properties & \\
Density of water, $\varrho w(l b / f t 3)$ & 62.40 \\
Oil API & 22.00 \\
Density of oil, $\varrho o(l b / f t 3)$ & 57.52 \\
Oil viscosity, $\mu$ o(cp) & 0.60 \\
Oil formation volume factor, Bo & 1.10 \\
Oil Saturation pressure, Pb(Psi) & 3769 \\
\hline
\end{tabular}

$Q o c=0.0783 \times 10^{-4}\left[\frac{(\varrho w-\varrho o) L D_{b}^{2} K_{h}}{\mu_{o} B_{o}\left(2 Y_{e}\right)}\right]\left[1-\frac{D_{b}^{2}}{Y_{e}^{2}}\right]\left(\frac{1}{24}\right)$

where $B=h-\mathrm{Db}$ and Db is distance between WOC and horizontal well, feet.

Joshi's method for critical rate calculation method:

$Q o c=0.0246 \times 10^{-4}\left[\frac{(\varrho w-\varrho o)\left(h^{2}-\left(h-D_{b}\right)^{2}\right) K_{h}}{\mu_{o} B_{o} \ln \left(\frac{r_{e h}}{r_{w}^{\prime}}\right)}\right]$

where $\varrho$ is density in $\mathrm{lb} / \mathrm{ft}^{3}, \mathrm{Kh}$ is horizontal permeability, $\mathrm{mD}, \mathrm{Db}$ is distance between WOC and horizontal well in feet, Dt is distance between horizontal well and GOC in feet, and rw is wellbore radius in feet.

CFPR calculation results from the various analytical methods are presented in Table 2 .

\section{Numerical simulation model}

The $50 \mathrm{~m}$ by $50 \mathrm{~m}$ gridding of the original model was upscaled to $100 \mathrm{~m}$ by $100 \mathrm{~m}$. The vertical resolution was reduced approximately by a factor of two, increasing average cell height from 0.5 to $1 \mathrm{~m}$. The geomodel was resampled into upscaled grid to capture rock types, porosity, and permeability and saturation distribution. The porosity was resampled arithmetically with weighing by pore volume. The resultant upscaled simulation grid has
Table 2 CFPR calculation results from the various analytical methods

\begin{tabular}{ll}
\hline Method & CFPR (STB/D) \\
\hline Efros & 24 \\
Krachers method & 24 \\
Joshi's method & 39 \\
\hline
\end{tabular}

Table 3 Statistics for different rock type

\begin{tabular}{lcrcc}
\hline Rock type & \% Fraction & So \% & K (md) & Phi \% \\
\hline 1 & 14.5 & 60.44 & 1157 & 22.25 \\
2 & 28.5 & 51.64 & 502 & 20.73 \\
3 & 33.1 & 37.66 & 220 & 18.29 \\
4 & 8.1 & 7.11 & 180 & 15.44 \\
5 & 15.8 & 1.35 & 157 & 10.96 \\
\hline
\end{tabular}

$120 \times 72 \times 86(7,43,040$ cells $)$ having 3,08,326 active cells, and upscaled model was migrated into the Eclipse Simulator. Further reduction on active blocks was carried out by reducing the number of grid blocks in aquifer region and conducting re-dimensions to the pore volume of the aquifer grid cell.

There were five rock types introduced in the model (rock type 1 to rock type 5). Rock type 1 is considered to be the best rock type, whereas rock type 5 is worst rock type considered for the study. Statistics of rock type distribution in terms of oil saturation, permeability, and porosity is given in Table 3. Porosity, permeability, and rock types distribution of the geomodel with well location are shown in Figs. 4, 5, 6, respectively.

\section{History matching}

Actual history rates and cumulative on oil, water, and gas for a total of 35 wells for a period of 10 years were simulated with a commercial black oil simulator. Results of the history match on reservoir scale are illustrated in Fig. 7. Well-wise gas oil ratio (GOR), water cut, and the flowing/static pressure data were used as history matching parameters. It can be seen that rates (oil rate, water rate), GOR, and pressure have been matched quite well with the actual history by the simulator at field level.

Well-49 coning behavior was also captured by the simulated model which is illustrated in Fig. 8. All figures show good match between simulated and actual production.

It is evident from Figs. 7 and 8 that dynamic model is capable of predicting historical production at field level as well as well level. This model can be used for doing 


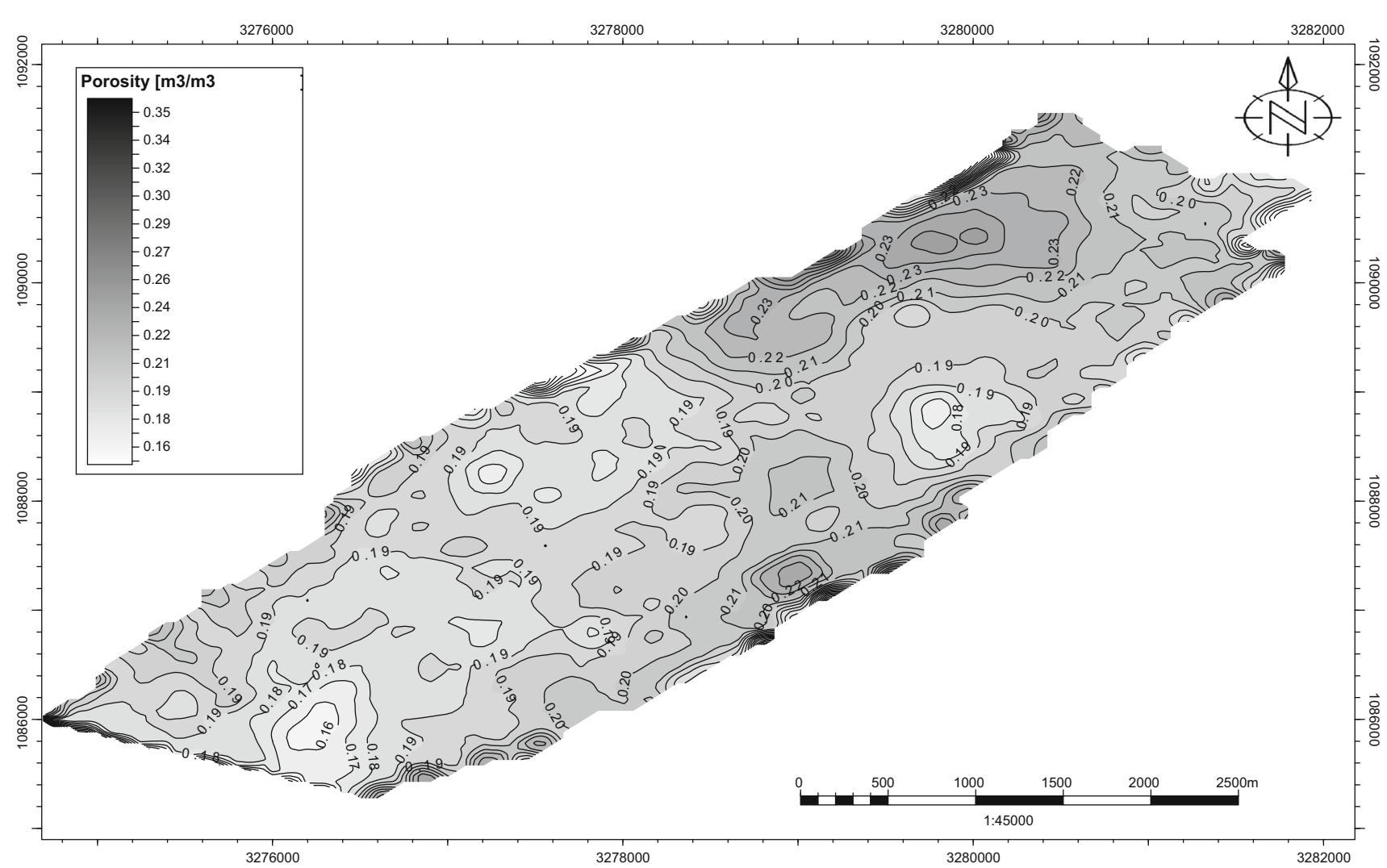

Fig. 4 Porosity distribution of the geomodel

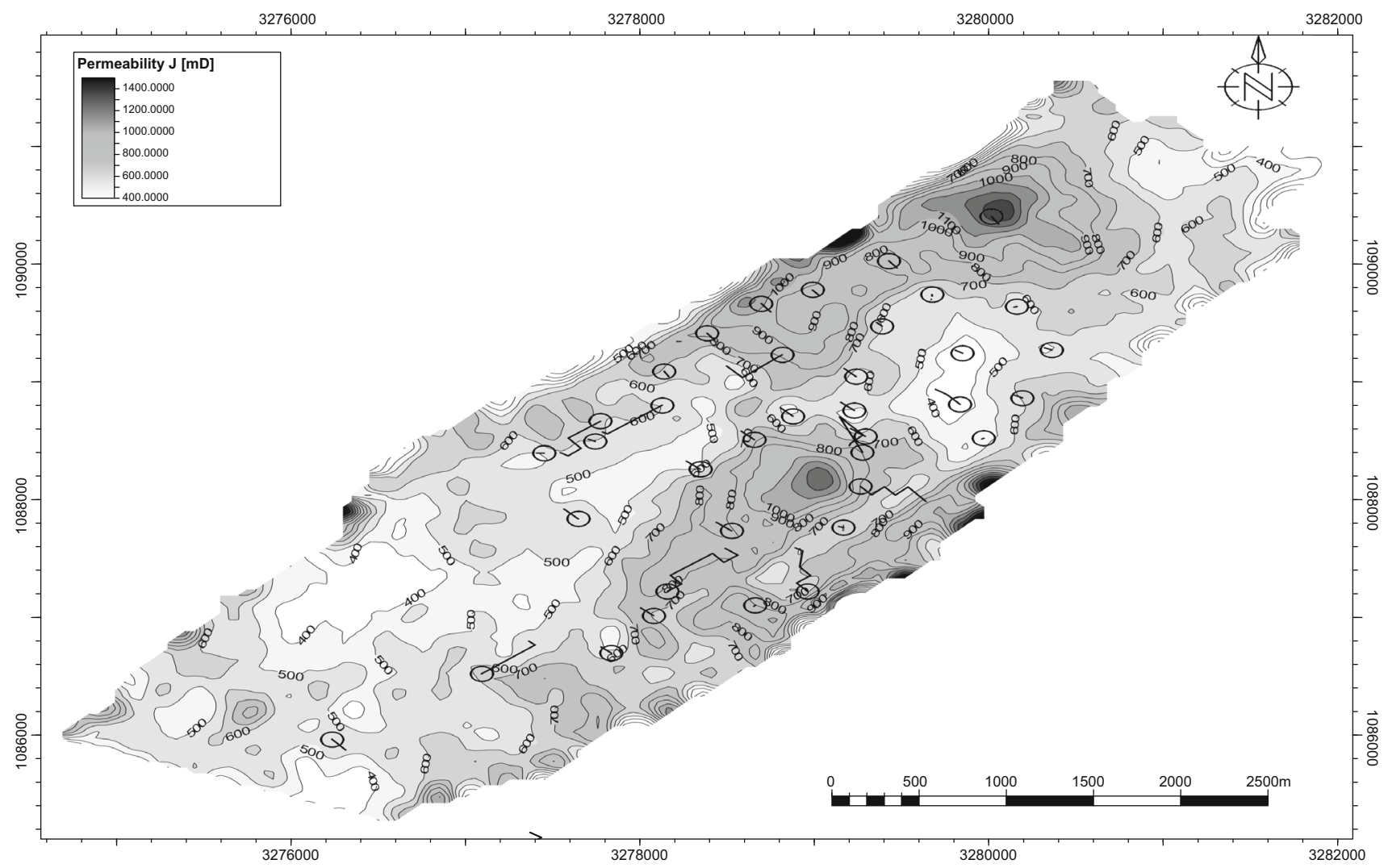

Fig. 5 Permeability distribution of the geomodel 


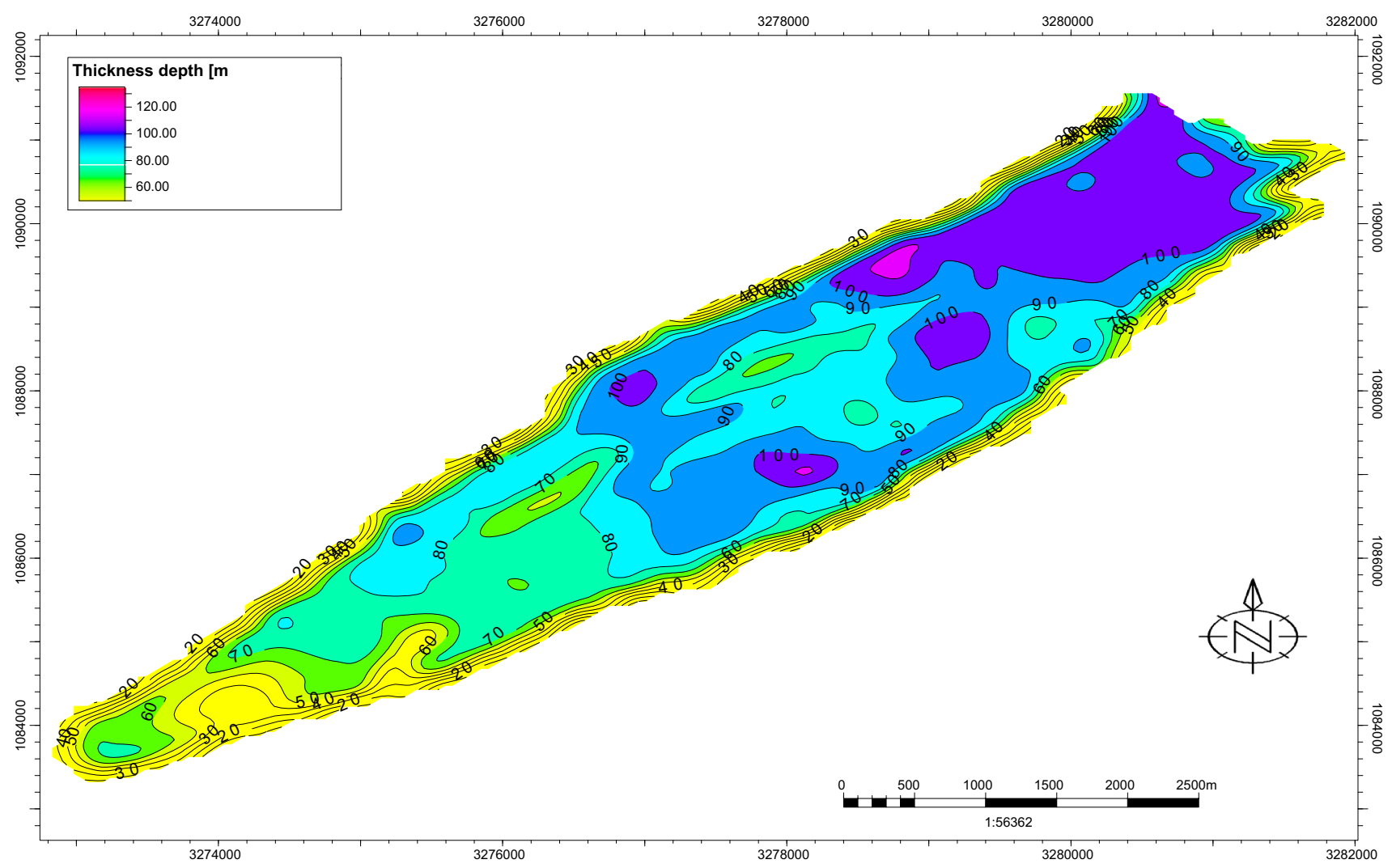

Fig. 6 Reservoir Thickness distribution of the geomodel
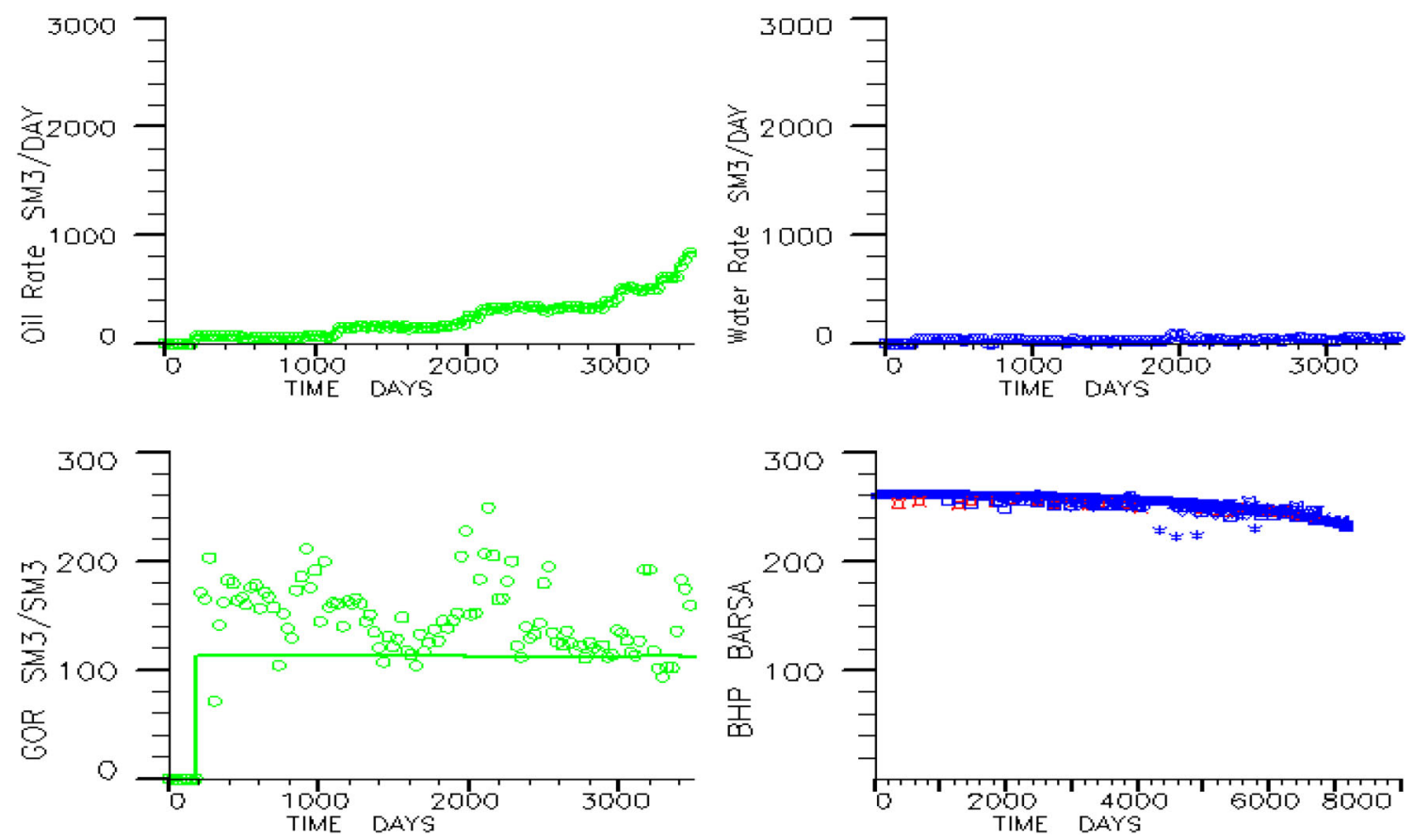

Fig. 7 History match results at field level 

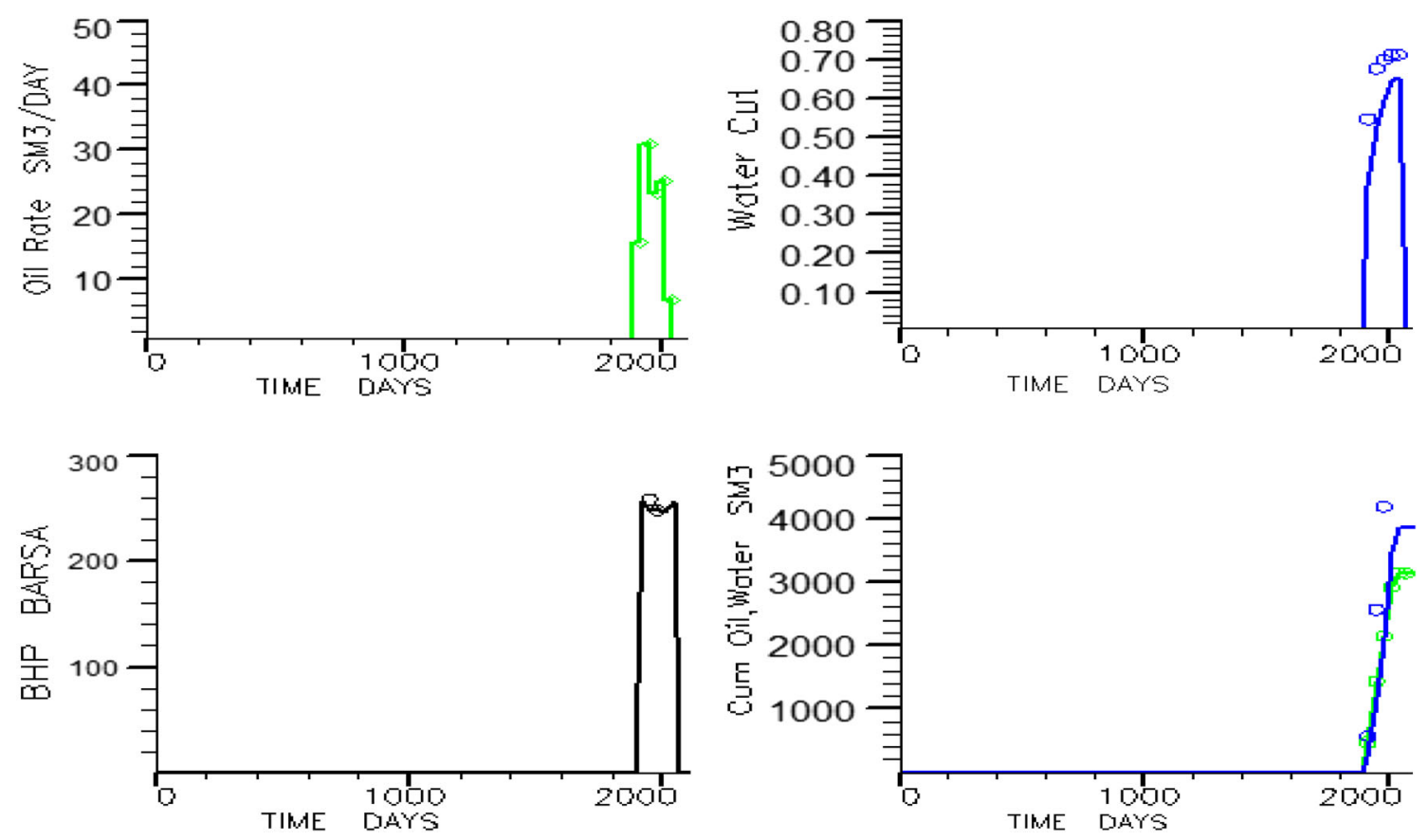

Fig. 8 History match results at well level for Well-49

sensitivity analysis for predicting hydrocarbon recovery with different variants such as liquid rate, offset from WOC.

\section{Sensitivity analysis}

This model was used to perform sensitivity analysis on rate and offset from WOC. All variants are mentioned in Table 4. From the above combination, fifteen (15) cases were constructed.

The prediction cases for reservoir were run using well production rate control. The well was given the production constraint as per the surface handling capacities. The wells were subjected to certain other constraints as shown in Table 5. From these 48 cases, four groups were constituted as per offset (Table 4).

Forty-eight (48) cases were simulated where twelve (12) cases were simulated for each offset from WOC. Outcome of the simulation runs have been presented from Figs. 9, $10,11,12$. Each figure has four plots, description of which is given below.

- Cumulative liquid produced at EOP and pressure drop for various horizontal lengths (A),

- Water cut at EOP and liquid rate for various horizontal lengths (B)

- Cumulative oil production and horizontal length for various liquid rates $(\mathrm{C})$

- Cumulative oil production and liquid rate for various horizontal lengths (D)
Table 4 Sensitivity parameters for Group-1 through Group-5

\begin{tabular}{|c|c|c|c|c|}
\hline \multicolumn{5}{|c|}{ Group-1-(5 m offset $)$} \\
\hline Perforation top & \multicolumn{4}{|l|}{$\mathrm{GOC}+2 \mathrm{~m}$} \\
\hline Rate $\left(\mathrm{m}^{3} /\right.$ day $)$ & 200 & 250 & 300 & \\
\hline Horizontal Length & 600 & 800 & 1000 & 1200 \\
\hline \multicolumn{5}{|c|}{ Group-2 (10 m offset) } \\
\hline Perforation top & \multicolumn{4}{|l|}{$\mathrm{GOC}+2 \mathrm{~m}$} \\
\hline Rate $\left(\mathrm{m}^{3} /\right.$ day $)$ & 200 & 250 & 300 & \\
\hline Horizontal length & 600 & 800 & 1000 & 1200 \\
\hline \multicolumn{5}{|c|}{ Group-3 (15 m offset) } \\
\hline Perforation top & \multicolumn{4}{|l|}{$\mathrm{GOC}+2 \mathrm{~m}$} \\
\hline Rate $\left(\mathrm{m}^{3} /\right.$ day $)$ & 200 & 250 & 300 & \\
\hline Horizontal length & 600 & 800 & 1000 & 1200 \\
\hline \multicolumn{5}{|c|}{ Group-4 (20 m offset) } \\
\hline Perforation top & \multicolumn{4}{|l|}{$\mathrm{GOC}+2 \mathrm{~m}$} \\
\hline Rate (m³/day) & 200 & 250 & 300 & \\
\hline Horizontal length & 600 & 800 & 1000 & 1200 \\
\hline
\end{tabular}

\section{Results and discussion}

Results of the simulation cases have been discussed for all the groups in the subsequent paragraphs.

\section{Group-1}

- Figure 9a: As rate is increased from 200 to $300 \mathrm{~m}^{3} /$ day, pressure drop (final reservoir pressure-initial reservoir pressure) increases for every horizontal length. 
Table 5 Well-level constraints for prediction runs

\begin{tabular}{ll}
\hline Constraints & Value \\
\hline Maximum individual well production rate & Decided based on historical well production rate in the reservoir \\
Completion type & Single completion: bottom-to-top \\
Minimum well bottom-hole pressure & $50-100$ bars, depending upon the segment performance \\
Maximum water cut & $95 \%$ \\
Minimum economic limit on oil rate & $1 \mathrm{~m}^{3} / \mathrm{day}$ \\
Maximum GOR constraint & $1500 \mathrm{~m}^{3} / \mathrm{m}^{3}$
\end{tabular}
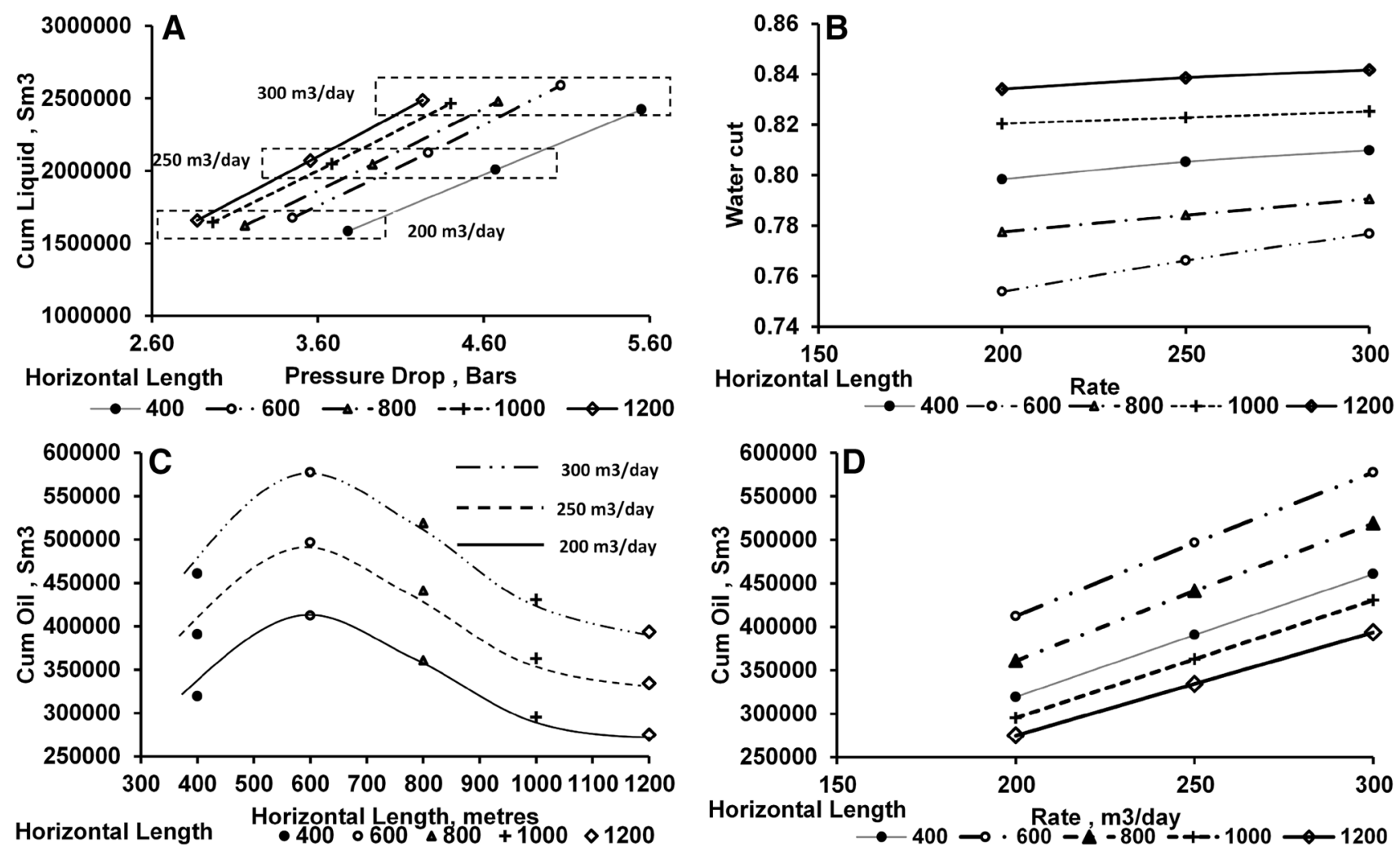

Fig. 9 Results of Group-1 simulation runs

- Figure 9b: As rate is increased from 200 to $300 \mathrm{~m}^{3} /$ day, water cut increases for all horizontal lengths.

- Figure 9c, d: As assigned liquid rate is increased from 200 to $300 \mathrm{~m}^{3} /$ day, cumulative oil production increases for all horizontal length sections examined. It can be seen that cumulative oil is maximum in case of $600 \mathrm{~m}$ horizontal length, which decreases on increasing horizontal length further.

\section{Group-2}

- Figure 10a As rate is increased from 200 to $300 \mathrm{~m}^{3} /$ day, pressure drop increases for every horizontal length.

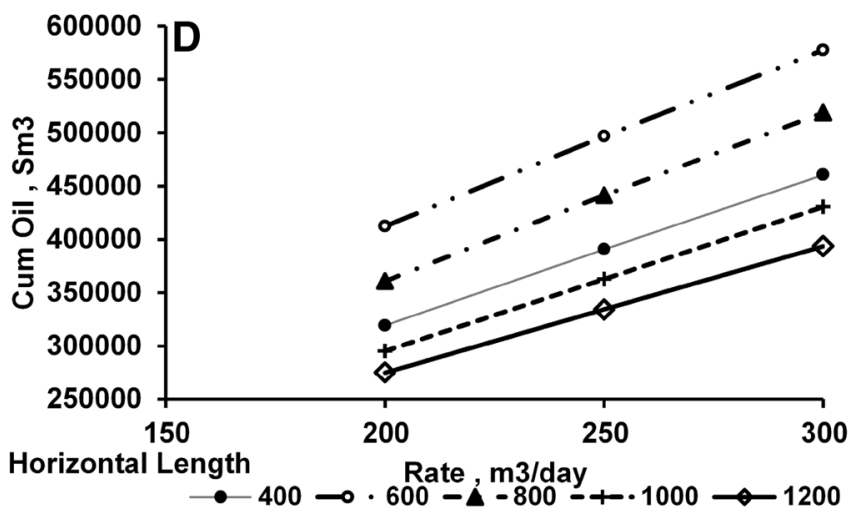

- Figure $10 \mathrm{~b}$ As rate is increased from 200 to $300 \mathrm{~m}^{3} /$ day, water cut increases for different horizontal lengths.

- Figure $10 \mathrm{c}, \mathrm{d}$ As assigned liquid rate is increased from 200 to $300 \mathrm{~m}^{3} /$ day, cumulative oil production increases for every horizontal length. It can be seen that cumulative oil is maximum in case of $800 \mathrm{~m}$ of either horizontal length, which decreases on increasing or decreasing horizontal length.

Group-3

- Figure 11a: As rate is increased from 200 to $300 \mathrm{~m}^{3} /$ day, pressure drop increases for every horizontal length. 

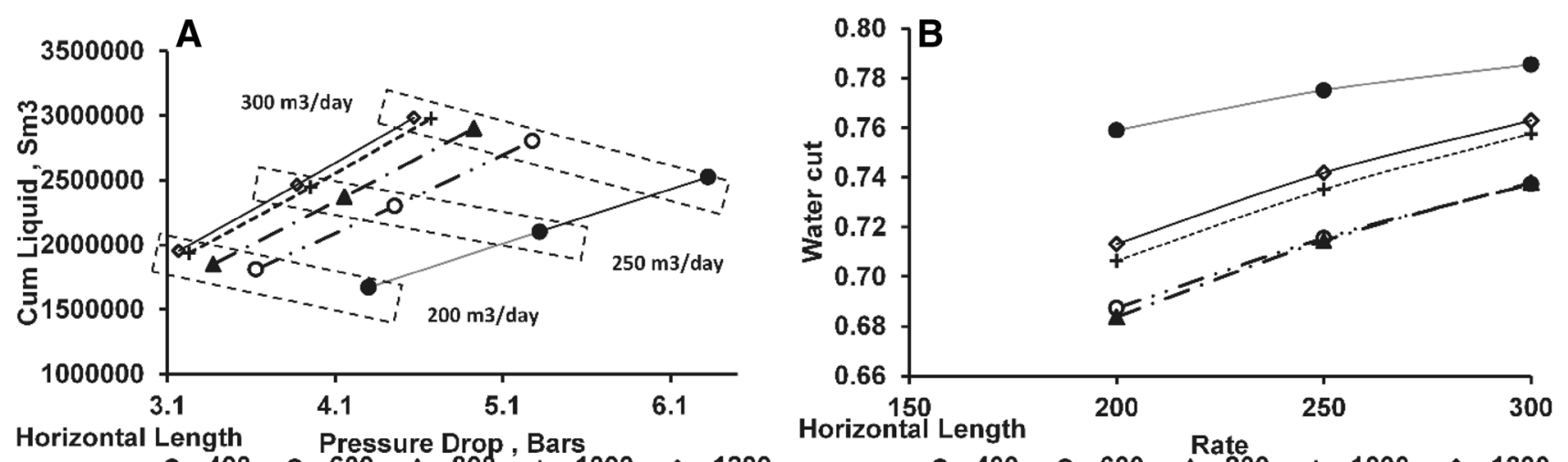

Horizontal Length $\begin{gathered}\text { Pressure Drop, Bars } \\ \longrightarrow-400 \multimap-600 \multimap-800--1000 \multimap-1200\end{gathered}$
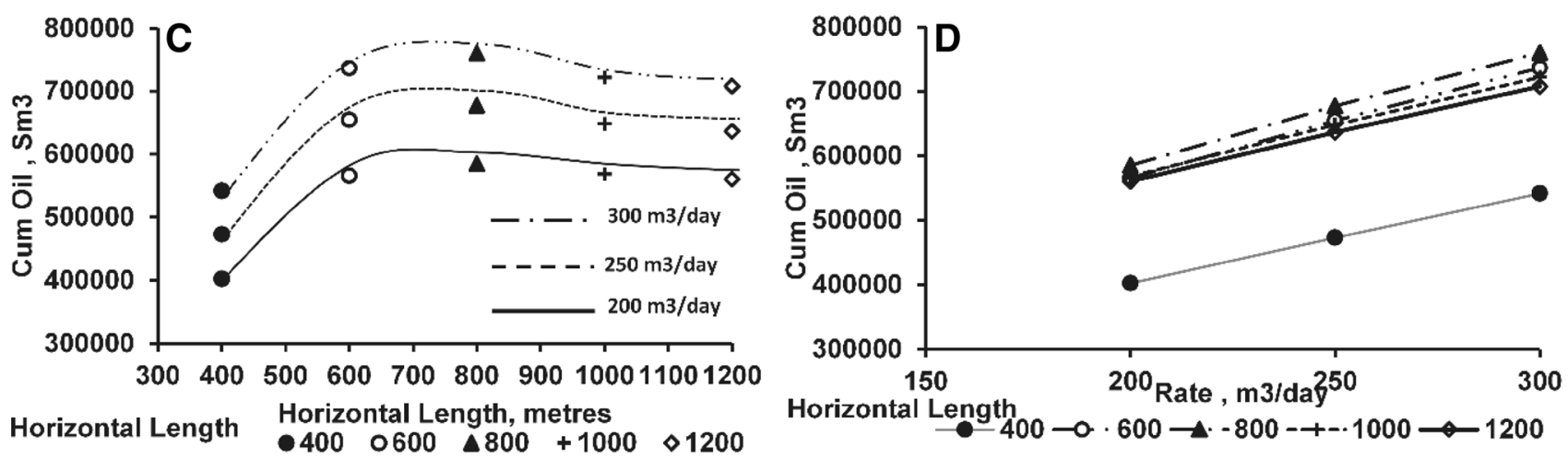

Fig. 10 Results of Group-2 simulation runs

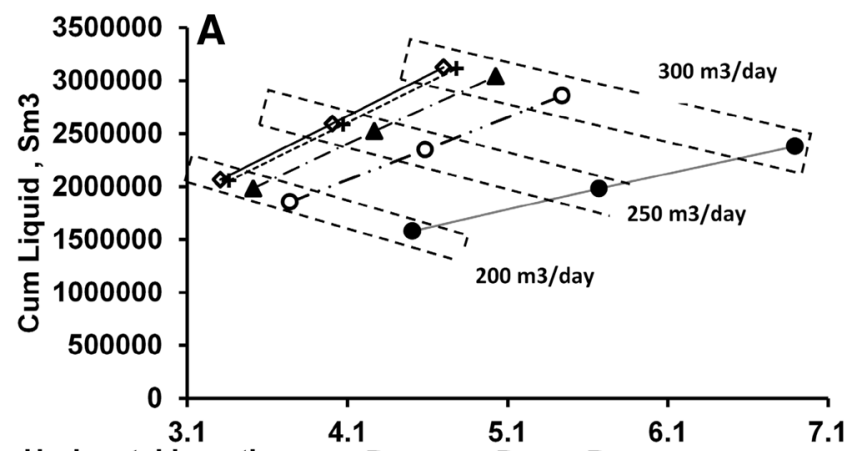

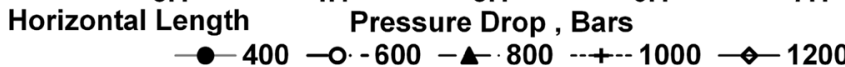
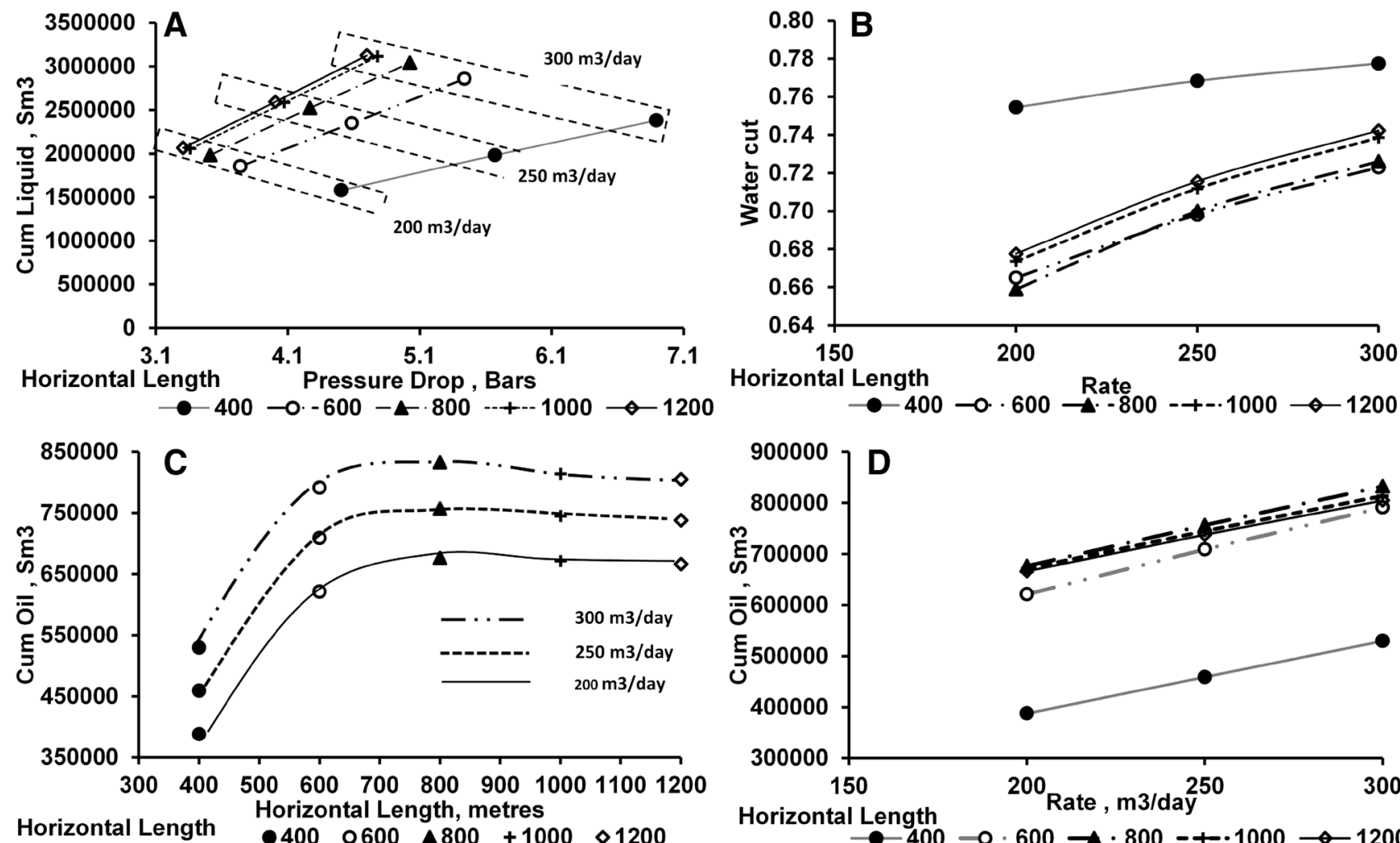

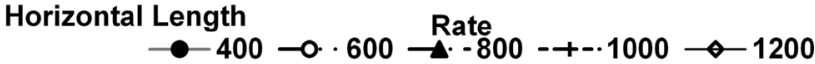

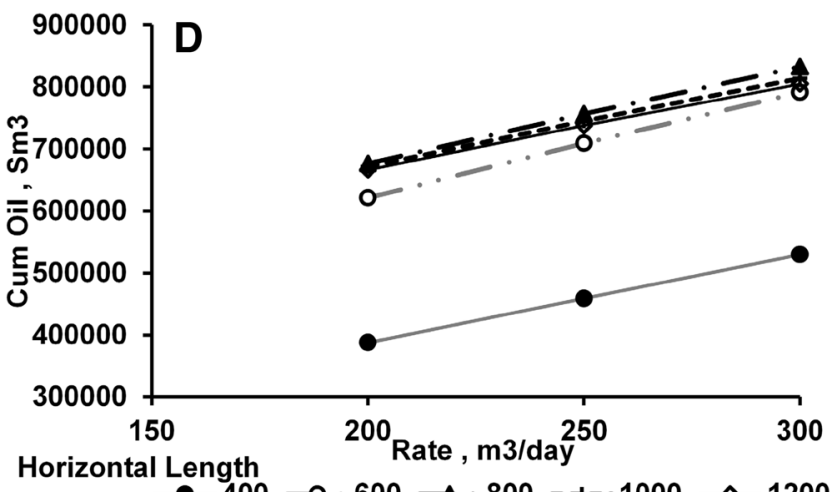

Fig. 11 Results of Group-3 simulation runs 

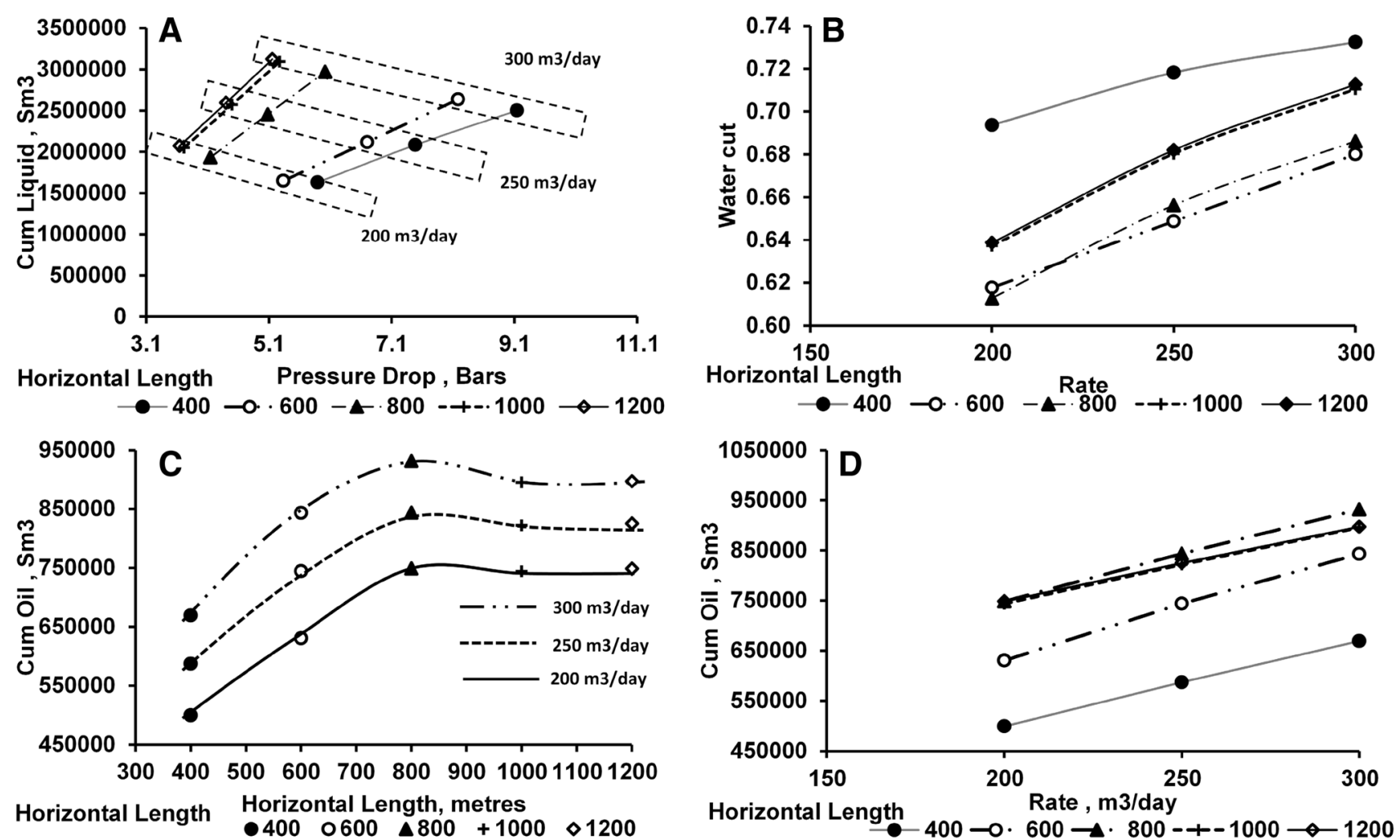

Fig. 12 Results of Group-4 simulation runs

- Figure $11 \mathrm{~b}$ As rate is increased from 200 to $300 \mathrm{~m}^{3} /$ day, water cut increases for different horizontal lengths.

- Figure 11c, d: As assigned liquid rate is increased, cumulative oil production increases for every horizontal length. It can be seen that cumulative oil is maximum in case of either $800 \mathrm{~m}$ horizontal length, which decreases on increasing or decreasing horizontal length.

\section{Group-4}

- Figure 12a: As rate is increased from 200 to $300 \mathrm{~m}^{3} /$ day, pressure drop increases for every horizontal length.

- Figure $12 \mathrm{~b}$ As rate is increased from 200 to $300 \mathrm{~m}^{3} /$ day, water cut increases for different horizontal length.

- Figure $12 \mathrm{c}$, d: As assigned liquid rate is increased cumulative oil, production increases for every horizontal length. It can be seen that cumulative oil is maximum in case of either $800 \mathrm{~m}$ horizontal length, which decreases on increasing or decreasing horizontal length.

Additionally, rate sensitivity for lower rates $(25,40,50,60$ and $70 \mathrm{~m}^{3} /$ day) was also carried out in the numerical simulation model. A plot of water cut vs time (Figure 13) for the above

cases shows that as rate is increased from 25 to $70 \mathrm{~m} 3 /$ day, water cut breakthrough time decreases gradually. For assigned rate of $25 \mathrm{~m}^{3} /$ day, water cut is constant and lowest among all simulation runs. Numerical value of $25 \mathrm{~m}^{3} /$ day is close to the analytical solution of critical rate calculated from various methods.

\section{Conclusions and recommendations}

From the above study, following can be concluded:

- Offset from WOC, horizontal length, and withdrawal rate have an impact on cumulative oil production in case of horizontal well. Maximum impact on cumulative oil production is given by offset from WOC followed by withdrawal rate and lastly on horizontal well length. Maximum recovery of $0.95 \mathrm{MMm}^{3}$ cumulative oil is obtained using optimum horizontal length of $600-800 \mathrm{~m}$, offset of $20 \mathrm{~m}$ and initial withdrawal rate of $300 \mathrm{~m}^{3} /$ day. Comparing the result from existing well-49, oil production cumulative of $0.152 \mathrm{MMm}^{3}$ is obtained throughout the production life with offset of $10 \mathrm{~m}$, horizontal length of $400 \mathrm{~m}$, and initial withdrawal rate of $200 \mathrm{~m}^{3} /$ day.

- As offset from WOC increases cumulative oil production increases until $15 \mathrm{~m}$ and then remains at almost same level. 


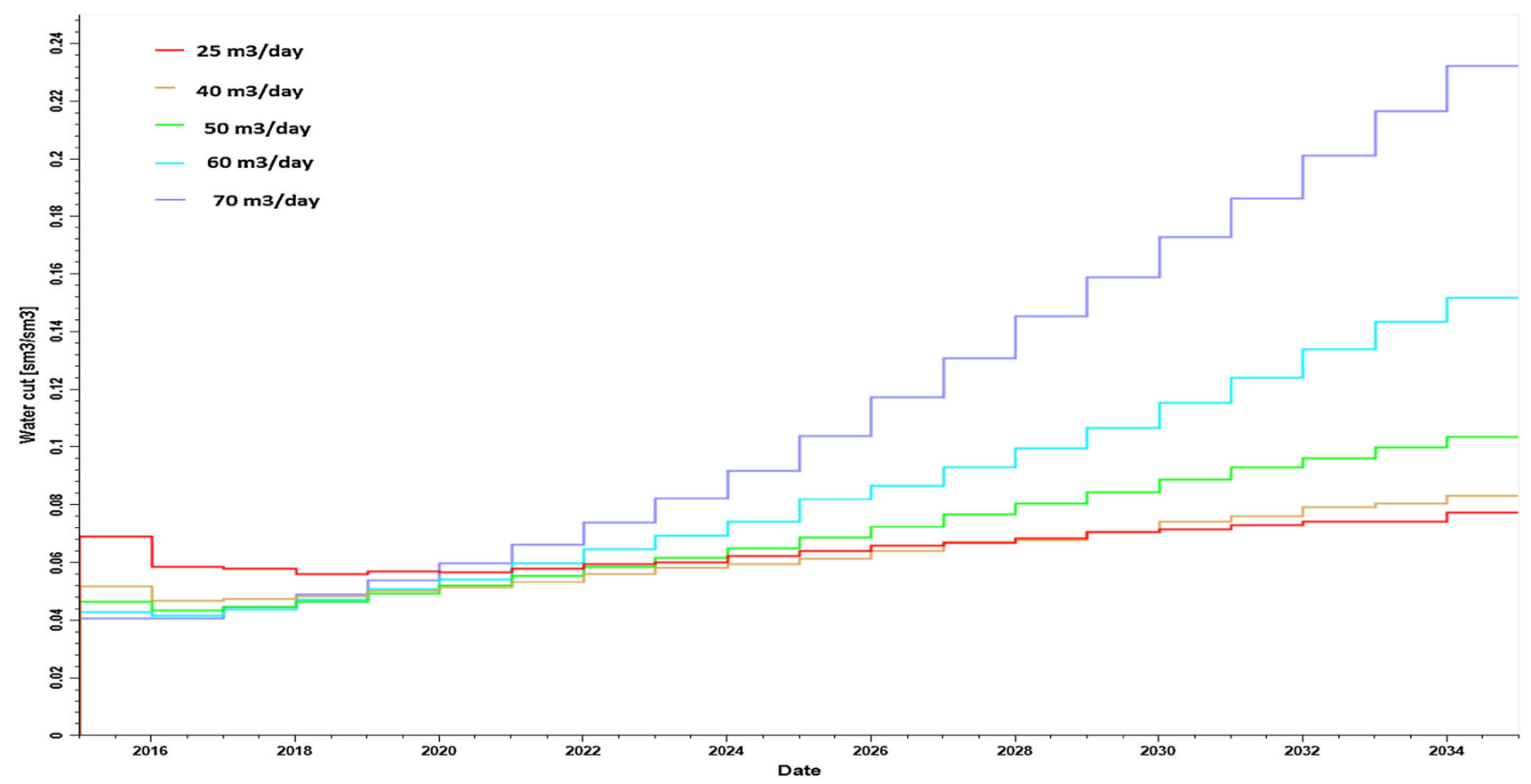

Fig. 13 Results of Group-4 simulation runs (for lower rates)

- Water cut reduces with increase in horizontal length and increases with higher withdrawal rate.

- For recovery, efficiency to be maximum horizontal length should be between 600 and $800 \mathrm{~m}$; further increase in horizontal length does not increase in cumulative oil production.

- As horizontal length is increased, pressure drop (final reservoir pressure-initial reservoir pressure) reduces.

Open Access This article is distributed under the terms of the Creative Commons Attribution 4.0 International License (http://creativecommons. org/licenses/by/4.0/), which permits unrestricted use, distribution, and reproduction in any medium, provided you give appropriate credit to the original author(s) and the source, provide a link to the Creative Commons license, and indicate if changes were made.

\section{Appendix}

See Table 6.

Table 6 Capillary pressure vs water saturation Lab Data

\begin{tabular}{llll}
\hline S No. & Well & PC(Psi)-Res & Sw@Plug-AV \\
\hline 1 & A-5 & 0.704166667 & 84.67 \\
2 & A-5 & 2.813055556 & 54.02 \\
3 & A-5 & 6.333888889 & 45.26 \\
4 & A-5 & 11.25944444 & 39.79 \\
5 & A-5 & 17.59333333 & 35.41 \\
6 & A-5 & 25.33194444 & 33.22 \\
7 & A-5 & 34.47888889 & 32.12 \\
\hline
\end{tabular}

Table 6 continued

\begin{tabular}{|c|c|c|c|}
\hline S No. & Well & PC(Psi)-Res & Sw@Plug-AV \\
\hline 1 & A-5 & 0.725833333 & 85.23 \\
\hline 2 & A-5 & 2.899722222 & 53.59 \\
\hline 3 & A-5 & 6.525277778 & 44.09 \\
\hline 4 & A-5 & 11.59888889 & 38.82 \\
\hline 5 & A-5 & 18.12055556 & 35.65 \\
\hline 6 & A-5 & 26.09388889 & 33.54 \\
\hline 7 & A-5 & 35.51888889 & 32.49 \\
\hline S No. & Well & PC(Psi)-Res & Sw@Plug-CV1 \\
\hline 1 & A-5 & 0.693333333 & 100 \\
\hline 2 & A-5 & 2.776944444 & 71.34 \\
\hline 3 & A-5 & 6.243611111 & 60.59 \\
\hline 4 & A-5 & 11.10055556 & 53.43 \\
\hline 5 & A-5 & 17.34416667 & 49.84 \\
\hline 6 & A-5 & 24.97805556 & 46.26 \\
\hline 7 & A-5 & 33.99861111 & 45.07 \\
\hline S No. & Well & PC(Psi)-Res & Sw@Plug-DV \\
\hline 1 & A-5 & 0.693333333 & 97.84 \\
\hline 2 & A-5 & 2.776944444 & 67.64 \\
\hline 3 & A-5 & 6.243611111 & 56.85 \\
\hline 4 & A-5 & 11.10055556 & 50.38 \\
\hline 5 & A-5 & 17.34416667 & 46.06 \\
\hline 6 & A-5 & 24.97805556 & 43.91 \\
\hline 7 & A-5 & 33.99861111 & 42.83 \\
\hline
\end{tabular}


Table 6 continued

\begin{tabular}{llll}
\hline S No. & Well & PC(atm)-Res & Sw@Plug2BH \\
\hline 1 & A-8 & 0 & 100 \\
2 & A-8 & 0.014168937 & 95 \\
3 & A-8 & 0.028337875 & 79 \\
4 & A-8 & 0.042506812 & 55 \\
5 & A-8 & 0.056675749 & 50 \\
6 & A-8 & 0.070844687 & 47 \\
7 & A-8 & 0.085013624 & 45 \\
8 & A-8 & 0.113351499 & 41 \\
9 & A-8 & 0.141689373 & 36 \\
10 & A-8 & 0.283378747 & 32 \\
11 & A-8 & 0.42506812 & 28 \\
12 & A-8 & 0.566757493 & 25 \\
13 & A-8 & 0.708446866 & 23 \\
14 & A-8 & 1.133514986 & 19 \\
15 & A-8 & 1.416893733 & 17 \\
16 & A-8 & 2.125340599 & 15 \\
17 & A-8 & 2.833787466 & 14 \\
18 & A-8 & 4.250681199 & 12 \\
19 & A-8 & 4.959128065 & 11 \\
20 & A-8 & 5.667574932 & 10.5 \\
\hline
\end{tabular}

\section{References}

Ahmed Tarek (2010) Water and gas coning, reservoir engineering handbook, 4th edn. Elsevier Science \& Technology, Oxford, pp 574-605
Al Hasani MA, Al Khayari SR, Al Maamari R, Al-Wadhahi MA (2008) Diagnosis of excessive water production in horizontal wells using WOR plots. Int Petrol Technol Conf. doi:10.2523/ 11958-MS

Dikken BJ (1990) Pressure drop in horizontal well and its effects on their production performance; Paper SPE19824. J Petrol Technol 42(11):1426-1433

Efros DA (1963) Study of multiphase flows in porous media. Gastoptexizdat, Leningrad (in Russian)

Hu Y, Zhou Y, Su Y, Huang M (2000) The design method for optimal horizontal well length. J Acta Petrolei Sinica 21(4):80-86

Hyun C (2003) Integrated optimization on a long horizontal well length; SPE-83669-PA. SPE Reservoir Eval Eng 6(02):81-88

Joshi SD (1988) Augmentation of well productivity using slant and horizontal wells. J Petroleum Technol 40(6):729-739

Joshi SD (2003) Cost/benefits of horizontal wells, SPE-83621-MS, SPE Western Regional/AAPG Pacific Section Joint Meeting, 19-24 May, Long Beach, California. doi 10.2118/83621-MS

Karcher B, Giger F, Combe J (1986) Some practical formulas to predict horizontal well behavior. SPE paper 15430, presented at the SPE 61st annual conference, New Orleans, October 5-8, 1986

Piper LD, Gonzalez FM (1987) Calculation of the critical oil production rate and optimum completion interval, SPE production operations symposium, 8-10 March, Oklahoma City, Oklahoma. doi:10.2118/16206-MS

Sharma UP, Mahto V, Sharma VP (2009) Advances in selection criteria of wells for gel placement. Drill Explor. Dev. 37-40

Zifei F, Fang H, Yu G (1997) A study on design method of optimal horizontal well length. J Acta Petrolei Sinica 18(1):55-62 